\title{
Bond Behavior of Fabric-Reinforced Geopolymeric Matrix System - A Pilot Study
}

\author{
Feras Abu Obaida ${ }^{1}$, Tamer El-Maaddawy ${ }^{1}$, Hilal El-Hassan ${ }^{1}$ \\ ${ }^{1}$ UAE University \\ Al Ain, UAE \\ feras.abuobaida@uaeu.ac.ae; tamer.maaddawy@uaeu.ac.ae; helhassan@uaeu.ac.ae
}

\begin{abstract}
This paper presents results of a pilot study carried out to investigate the feasibility and viability of producing a sustainable and eco-friendly structural strengthening solution involving the use of cement-free alkali-activated geopolymeric matrix and carbon fabric textiles. The study focused on examining the bond behavior at the fabric-geopolymeric matrix interface through single-lap shear tests. The geopolymeric matrix was a blend of fly ash/ground granulated blast furnace slag (GGBS) activated by an alkaline solution of sodium silicate and sodium hydroxide. Test parameters included the bonded length, configuration of the textile fabrics, and composition of the matrix. The bond behavior of the specimens with a geopolymeric matrix was characterized and compared to that of similar specimens with a cementitious matrix. All specimen exhibited a debonding mode of failure at the fabric-matrix interface. The bond strength of a specimen with a bi-directional fabric was higher than that of a similar specimen with a unidirectional fabric. The bond strength of the specimens with the geopolymeric matrix was even higher than that of similar specimens with the cementitious matrix. Increasing the fly ash-to-GGBS ratio in the geopolymeric matrix slightly decreased the bond strength but improved the post-peak behavior of the tested specimens.
\end{abstract}

Keywords: Bond, cementitious, geopolymer, fabrics, textiles, strengthening.

\section{Introduction}

Conventional fabric-reinforced cementitious matrix (FRCM) strengthening systems involves bonding of fabric grids to the concrete substrate using a cementitious bonding agent [1]. The bond behavior at the fabric-matrix interface in fabricreinforced cementitious matrix systems has been the focus of many studies. Hashemi and Al-Mahaidi [2] reported that the cementitious mortar provided better bond with fabric textiles than fabric sheets. The failure mode was typical of interfacial cracking between the mortar and fibers. D'Ambrisi et al. [3-4] studied the bond-slip relations at the interface between Poliparafenilen BenzobisOxazole (PBO) fabrics and a cementitious matrix. The specimens failed by debonding at the fabricmatrix interface, followed by considerable slippage of fabric. A thin layer of the matrix remained perfectly attached to the concrete substrate. The bond strength at the fabric-matrix interface increased with an increase in the bond length up to an effective length, where the bond capacity remained constant. This effective bond length was approximately $250 \mathrm{~mm}$. The obtained bond-slip relations were characterized by a pronounced descending branch, up to a slip value of $1 \mathrm{~mm}$, and by a low maximum shear stress of approximately 0.6 MPa. Sneed et al. [5-6] reported that the bond strength at the fabric-matrix interface increased with an increase in the bond length. The effective bond length was approximately $250 \mathrm{~mm}$. Failure was characterized by considerable slippage between the fibers and matrix, with no damage to the matrix-concrete interface. Ombres et al. [7] reported that the fabric strain recorded in bond tests decreased as the number of fabric layers increased. The failure mode also shifted from fabric slippage to delamination at the fabric-matrix interface. The effective bond length was found to be in the range of 150-200 mm. Donnini et al. [8] investigated the bond behavior of fabric-reinforced cementitious matrix systems employing carbon fabrics with different coating treatments. In double shear tests, the use of a coating improved the bond at the matrix-fiber interface. In pull-out tests, the predominant failure mode was at the interface between the fabric and matrix.

Although the inclusion of a cementitious mortar in the fabric-reinforced cementitious matrix strengthening system, rather than epoxy, improves the heat-fire resistance and the compatibility with the concrete substrate, the production of cementbased materials consumes significant amount of non-renewable natural resources and leads to an increase in the concentration of $\mathrm{CO}_{2}$ in the atmosphere. The cement industry is accountable for 5-7\% of the global $\mathrm{CO}_{2}$ emissions [9-10], leading to an 
increase in the concentration of $\mathrm{CO}_{2}$ in the atmosphere [11-12]. As a result, cement production is becoming a critical global issue from an ecological, social, and environmental standpoint. The use of inorganic alkali-activated geopolymeric matrices with ground industrial waste materials, alternative to the polymeric resins and cementitious mortars, would offer a sustainable and eco-friendly strengthening solution. Few studies focused on studying the structural behavior of concrete elements strengthened with fabric-reinforced geopolymeric matrix (FRGM) strengthening systems [13-15]. Vasconcelos et al. [13] employed metakaolin-based geopolymer mortar as a sustainable alternative to commercial mortars. Findings showed that the proposed inorganic matrix was as effective as epoxy in increasing the strength and stiffness of reinforced concrete beams. However, strengthening using geopolymers showed a more brittle failure mechanism. Menna et al. [14] studied the effectiveness of using steel cords embedded in a metakaolin-based geopolymeric matrix to strengthen concrete beams. The results highlighted a very good adhesion between the matrix, concrete substrate and steel cords, leading to an increase in the bending moment capacity of the strengthened beams. Conversely, debonding mechanisms occurred between carbon fibers and geopolymer matrix when carbon fiber-reinforced geopolymer system was used. This was attributed to the poor bond at the carbon fibers-matrix interface and inability to fully impregnate the carbon fibers. Due to its limited fluidity, the geopolymer matrix was unable to penetrate into the carbon fiber filament yarns and transfer the load to the carbon fiber reinforcement. Bencardino et al [15] examined the bond behavior of steel-reinforced geopolymeric matrix-concrete joints in single-lap shear bond tests. An effective bond length of $200 \mathrm{~mm}$ was required to develop the maximum bond strength. The joints experienced debonding at the steel cords-matrix interface, except for specimens with a bonded length of $100 \mathrm{~mm}$, where debonding developed at the matrix-concrete interface. The mean values of fracture energy, maximum shear bond stress and corresponding slip were equal to $0.54 \mathrm{~N} / \mathrm{mm}, 1.76 \mathrm{MPa}$ and $0.12 \mathrm{~mm}$, respectively.

There is a lack of knowledge about the bond behavior at the fabric-geopolymeric matrix interface. More research is needed to examine the feasibility of producing a cement-free fabric-reinforced geopolymeric matrix to be used in structural strengthening as a sustainable alternative to commercial cement-based mortars. The bond behavior at the fabric-matrix interface is a key element affecting the overall structural behavior of strengthened concrete structures. Characterization of the bond behavior at the fabric-geopolymeric matrix interface is needed before FRGM systems can be routinely used as a structural strengthening solution in practical setting. The current pilot study is considered a step towards filling this research gap. Five single-lap shear tests were conducted. Test variables included the bonded length, type of fabric/textile, and type of matrix. Test results in terms of failure mode, bond strength, and load-global slip relationships are reported and discussed.

\section{Experimental Program}

Single-lap shear bond tests were carried out on five specimens to investigate the bond characteristic of different FRCM and FRGM systems. Two types of carbon fabrics were used, namely, carbon-1 and carbon-2. The specimens were categorized into two groups; [A] and [B], based on the type of matrix used, as indicated in Table 1. Group [A] had two specimens. Both of them had a fabric type of carbon-1 and a bond length of $100 \mathrm{~mm}$. In one specimen, the matrix was geopolymer-1 whereas the matrix for the other specimen was geopolymer-2. Group [B] had three specimens. All of them had a cementitious matrix. Two specimens had a fabric type of carbon-1 with a bond length of either 100 or 300 $\mathrm{mm}$. The remaining specimen had a fabric type of carbon-2 with a bond length of $100 \mathrm{~mm}$.

Table 1: Test matrix.

\begin{tabular}{|l|l|l|l|l|}
\hline Group & Mortar type & Fabric type & $\begin{array}{l}\text { Bond length } \\
(\mathrm{mm})\end{array}$ & Specimen \\
\hline \multirow{2}{*}[\mathrm{A}]{} & Geopolymer -1 & Carbon-1 & 100 & GP1-C1-100 \\
\cline { 2 - 5 } & Geopolymer -2 & Carbon-1 & 100 & GP2-C1-100 \\
\hline \multirow{2}{*}[\mathrm{B}]{} & Cementitious & Carbon-1 & 100 & CM-C1-100 \\
\cline { 3 - 5 } & & Carbon-2 & 100 & CM-C2-100 \\
\cline { 3 - 5 } & & Carbon-1 & 300 & CM-C1-300 \\
\hline
\end{tabular}




\subsection{Materials}

Geopolymer-1 and geopolymer-2 were fly ash/GGBS blended matrices activated by an alkaline solution of sodium silicate and sodium hydroxide. Fig. 1(a) and (b) show the as-received fly ash and GGBS, respectively. While geopolymer-1 had a fly ash-to-GGBS ratio of 1:3, that of geopolymer-2 was 1:1. The proposed geopolymeric blend serves to eliminate the need for heat curing in fly ash-based geopolymers and to reduce the drying shrinkage in GGBS-based geopolymers. Each cementitious mortar used was a commercial adhesive recommended by the designated fabric manufacturer. The geopolymer1 and geopolymer-2 matrices had compressive strengths of 51 and $43 \mathrm{MPa}$, tensile strengths of 6.5 and $5.5 \mathrm{MPa}$, and tensile moduli of 36 and $33 \mathrm{GPa}$, respectively. The commercial mortars used with carbon- 1 and carbon- 2 fabrics had compressive strengths of 65 and $45 \mathrm{MPa}$, tensile strengths of 7 and $6 \mathrm{MPa}$, and tensile moduli of 35 and $30 \mathrm{GPa}$, respectively (data was obtained from the manufacturer).

Two types of carbon fabrics were used in this study. The first type of carbon fabric, carbon-1, was a bi-directional. It was made of joint carbon fiber bundles (rovings) processed on sewing machines to produce textile grids. The longitudinal and transverse carbon rovings had a thickness of approximately $1 \mathrm{~mm}$ and center-to-center spacings of $10 \mathrm{~mm}$ and $18 \mathrm{~mm}$, respectively [Fig. 2(a)]. Each roving had a width of approximately $3 \mathrm{~mm}$ in the longitudinal (weft) direction and $6 \mathrm{~mm}$ in the transverse (warp) direction. The second type of carbon fabric, carbon-2, was unidirectional. The rovings had a center-tocenter spacing of $17 \mathrm{~mm}$. Each roving had a width of approximately $5 \mathrm{~mm}$ and a thickness of $0.54 \mathrm{~mm}$ [Fig. 2(b)]. The properties of the two types of fabrics, as provided by the manufacturer, are listed in Table 2.

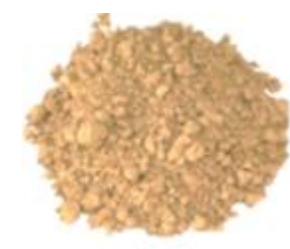

(a)

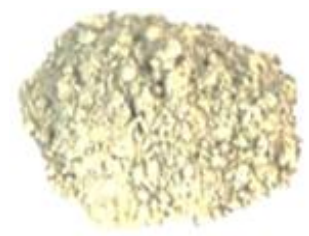

(b)

Fig. 1: As-received (a) fly ash and (b) GGBS.

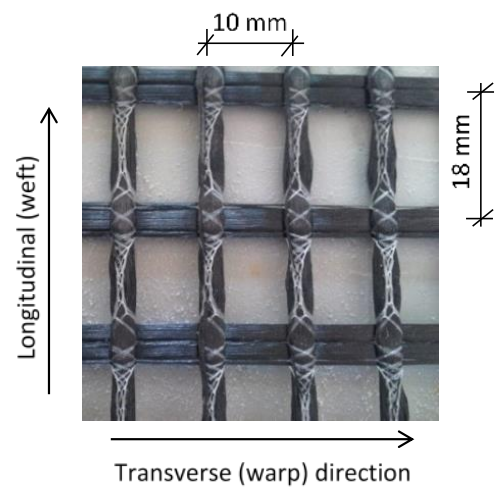

(a)

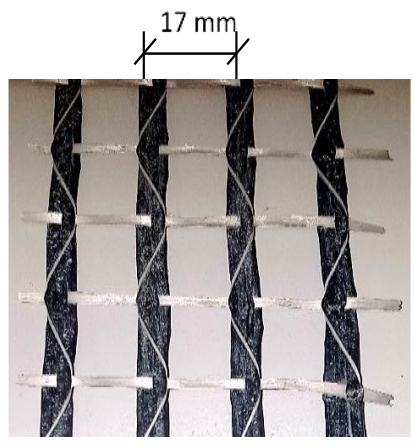

(b)

Fig. 2: Types of fabrics; (a) carbon-1, (b) carbon-2.

Table 2: Properties of fabrics (data was obtained from the manufacturer).

\begin{tabular}{|l|c|c|}
\hline Property & Carbon-1 & Carbon-1 \\
\hline Area weight $\left(\mathrm{g} / \mathrm{m}^{2}\right)$ & 609 & 281 \\
\hline Tensile strength $(\mathrm{MPa})$ & 3,800 & 4,300 \\
\hline Modulus of elasticity $(\mathrm{GPa})$ & 230 & 240 \\
\hline Elongation at break $(\%)$ & 1.6 & 1.75 \\
\hline
\end{tabular}




\subsection{Test Set-up}

Specimens of the bond tests comprised one FRCM or FRGM layer bonded to a concrete prism as shown in Fig. 3. The concrete prism had a cross section of $150 \times 150 \mathrm{~mm}$ and a total length of $600 \mathrm{~mm}$. The FRCM/FRGM were bonded to the $150 \times 600 \mathrm{~mm}$ concrete face. The width of the matrix in all specimens was kept constant at $50 \mathrm{~mm}$, whereas the bonded length was either a 100 or $300 \mathrm{~mm}$. The surface area of the fabrics was calculated based on the number of fabric bundles (rovings) embedded within the matrix. FRCM/FRGM were pulled out of a restrained concrete prism in a classical push-pull configuration. Tests were conducted under displacement control at a rate of $0.5 \mathrm{~mm} / \mathrm{min}$ using a servo-hydraulic universal MTS testing machine. The concrete prism was restrained against movement by means of a closed steel frame bolted to the base of the universal MTS testing machine. The global slip is defined as the relative displacement between points on the FRCM or FRGM just outside the bonded area and the adjacent surface of the concrete prism. Global slip was measured using two linear variable displacement transducers (LVDTs) reacted off of a thin aluminum L-shaped plate attached to the fabric in the proximity of the bonded area. A data acquisition system was used to record the loads and displacements. A schematic of the test set-up is shown in Fig. 3(a) whereas a test in progress is shown in Fig. 3(b).

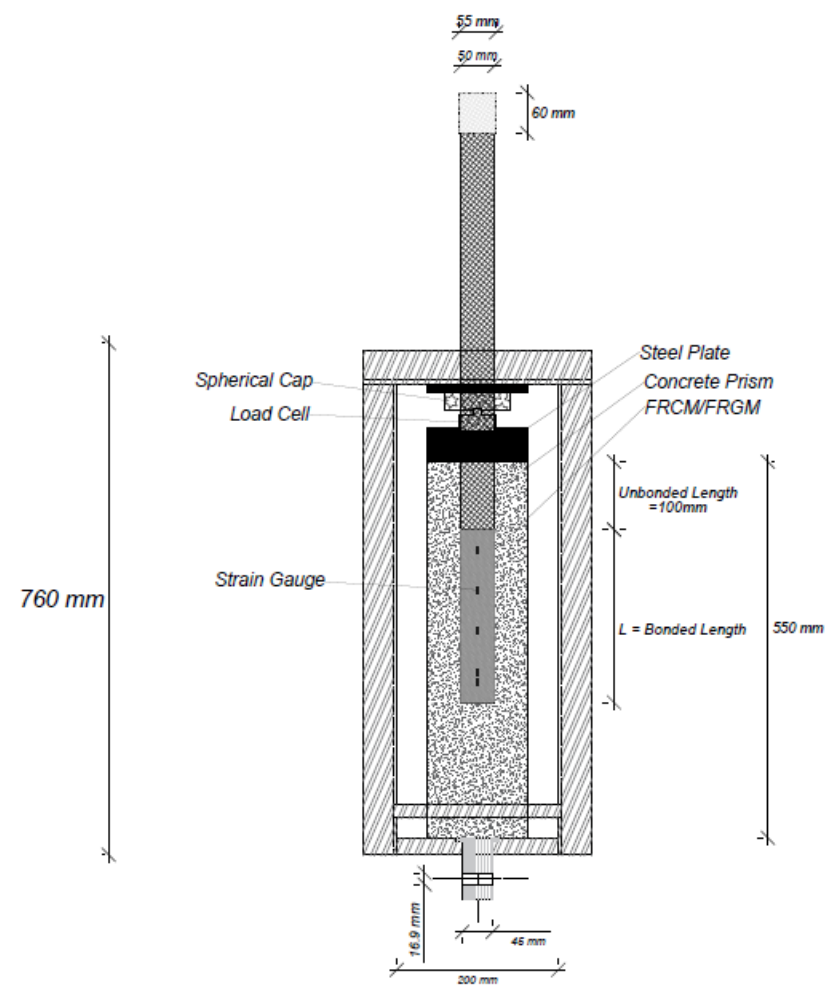

(a)

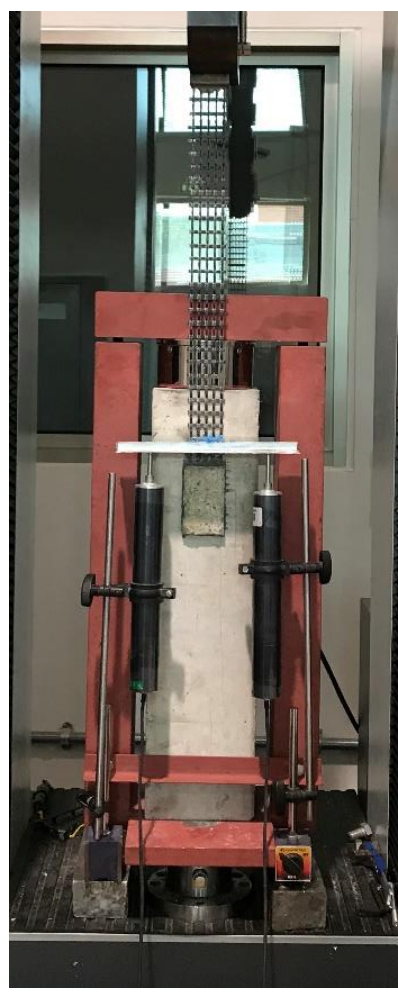

(b)

Fig. 3: Bond test; (a) schematic of test specimen and set-up, (b) preliminary test in progress.

\section{Test Results}

Results of the current pilot study are presented in this section. The results included, load-global slip relationships, maximum load, and failure mode.

\subsection{Failure Mode}

All specimens exhibited a debonding mode of failure at the fabric-matrix interface. In the initial stage of the test (i.e. prior to cracking), the fabric elongated and intermittent explosive sounds were heard indicating local damage matrix 
and/or debonding at the fabric-matrix interface. In most of the specimens, failure initiated by formation of a horizontal crack in the proximity of the loaded end. The first crack weakened the composite action at the fabric-matrix interface. Following initial cracking, the first crack widened and another crack formed below the one initiated earlier. As the load progressed, the cracks widened, slippage of fabrics occurred, followed by a complete delamination at the fabric-matrix interface. Fig. 4 summarizes stages of failure.

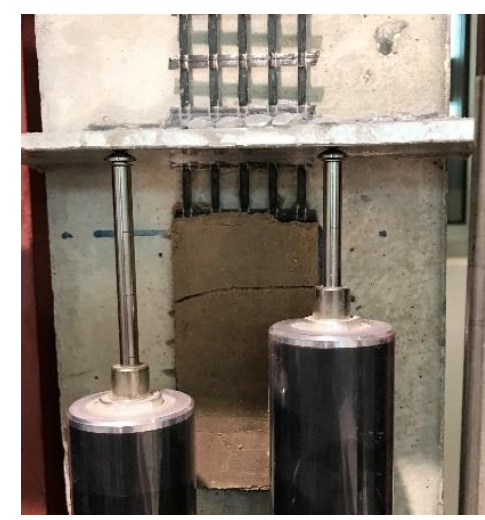

Initiation of first crack

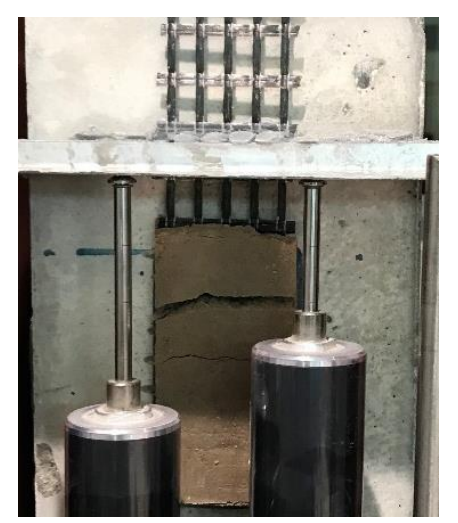

Widening of cracks and slippage

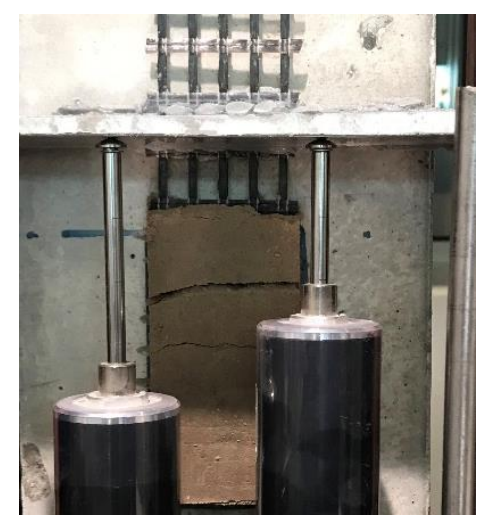

Initiation of second crack

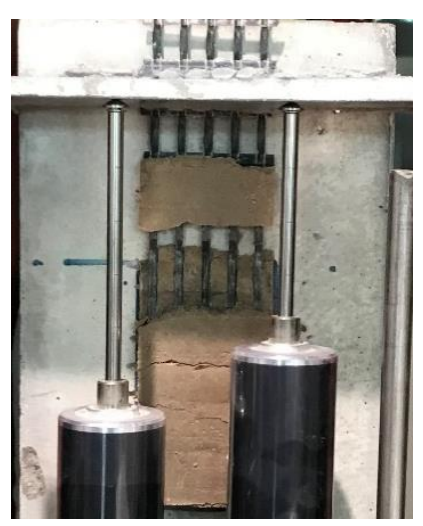

Complete delamination

Fig. 4: Typical failure mode (specimen GP2-C1-100).

\subsection{Load-Global Slip Relationship}

The load versus the global slip for specimens of groups [A] and [B] are depicted in Figs. 5 and 6, respectively. The results are summarized in Table 3 . The results confirm the feasibility and effectiveness of using cement-free alkali-activated geopolymeric matrices to produce sustainable and eco-friendly FRGM systems for structural strengthening application. The maximum load of specimen GP1-C1-100 was 9\% higher than that of specimen GP2-C1-100. After reaching the peak load, specimen GP1-C1-100 exhibited a sharp drop in load whereas specimen GP2-C1-100 was able to sustain more deformation with a gradual reduction in load. This can be attributed to the fly ash-to-GGBS ratio used in the geopolymeric blend. Increasing the amount of fly ash in the geopolymeric matrix slightly decreased the maximum load but improved the postpeak response. The maximum load of specimens GP1-C1-100 and GP2-C1-100 with the geopolymeric matrix was on average $28 \%$ higher than that of their counterpart specimen CM-C1-100 with the cementitious matrix. The fabric's configuration had an effect on the maximum load of the specimens with the cementitious matrix. Although the surface area of the fabric rovings in specimen CM-C1-100 was lower than that of specimen CM-C2-100, the maximum load of the former specimen was higher by approximately $13 \%$. This is because specimen $\mathrm{CM}-\mathrm{C} 1-100$ had a bi-directional carbon fabric whereas the fabric of specimen CM-C2-100 was unidirectional. This indicated that the mechanical interlock offered by the bi-directional fabrics improved the bond. Although the bond length of specimen CM-C1-300 was three times that of specimen CM-C1-100, the maximum load was only $20 \%$ higher. This is because of the fact that there is an effective bond length, beyond which, no 
significant increase in the maximum load occurs. The effective bond length is typically in the range of 150 to $250 \mathrm{~mm}$ $[5-7,15]$. As such, it would be misleading to calculate values of the bond strength $\left(\tau_{\max }\right)$ based on results of specimens with a bonded length greater than the effective bond length.

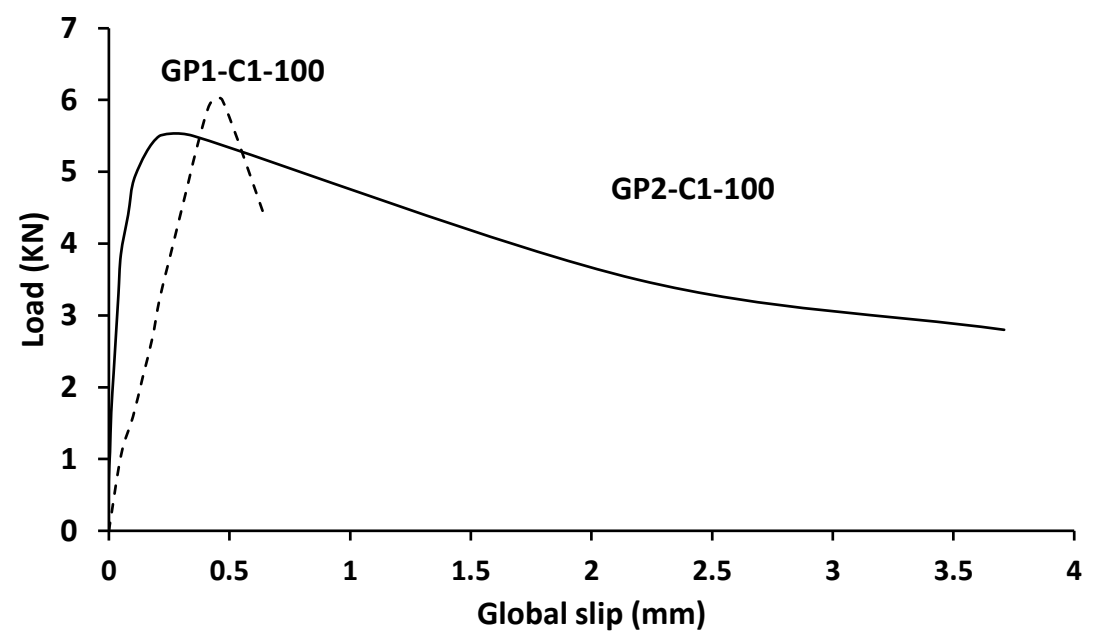

Fig. 5: Load-global slip of specimens of group [A].

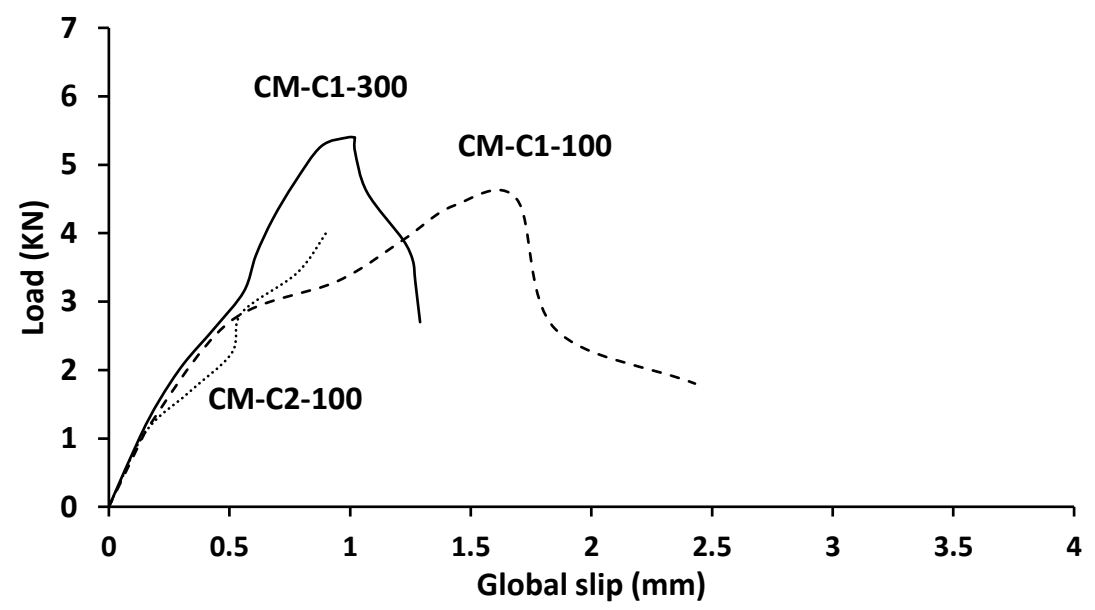

Fig. 6: Load-global slip of specimens of group [B]. 
Table 3: Maximum load and bond strength test results

\begin{tabular}{|l|l|l|l|l|l|}
\hline Group & Fabric type & $\begin{array}{l}\text { Bond } \\
\text { length } \\
(\mathrm{mm})\end{array}$ & $\begin{array}{l}\text { Surface area of } \\
\text { fabric rovings } \\
\left(\mathrm{mm}^{2}\right)\end{array}$ & $\begin{array}{l}\text { Maximum } \\
\text { load, } P_{\max }(\mathrm{N})\end{array}$ & $\begin{array}{l}\text { Bond strength, } \\
\tau_{\max }(\mathrm{MPa})\end{array}$ \\
\hline \multirow{3}{*}[\mathrm{A}]{} & GP1-C1-100 & 100 & 3000 & 6000 & 2.00 \\
\cline { 2 - 6 } & GP2-C1-100 & 100 & 3000 & 5500 & 1.83 \\
\hline \multirow{4}{*}[\mathrm{B}]{} & CM-C1-100 & 100 & 3000 & 4500 & 1.50 \\
\cline { 2 - 6 } & CM-C2-100 & 100 & 4000 & 4000 & 1.00 \\
\cline { 2 - 6 } & CM-C1-300 & 300 & 10800 & 5400 & N.A. ${ }^{*}$ \\
\hline
\end{tabular}

*Bonded length is greater than the effective bond length

\section{Conclusion}

Single-lap shear bond tests were conducted on five specimens to investigate the bond behavior of FRGM-concrete joints. Results of the joints with a geopolymeric matrix were compared to those of similar specimens with a cementitious matrix. The results confirmed the feasibility and viability of producing and employing geopolymeric matrices as sustainable alternatives to commercial mortars used in structural strengthening systems involving carbon fabric grids/textiles. The bond strength of the specimens with a geopolymeric matrix was even higher than that of the specimens with a cementitious matrix. The geometry of the fabric affected the bond strength. The bond strength of a specimen with a bi-directional fabric was $50 \%$ higher than that of a similar specimen with a unidirectional fabric. The composition of the geopolymeric matrix also affected the bond behavior. Increasing the fly ash-to-GGBS ratio slightly decreased the bond strength. Nevertheless, the post-peak behavior of the tested specimens improved by increasing the fly ash-to-GGBS ratio. Future work will focus on testing bond specimens with a bonded length in the range of 50 to $300 \mathrm{~mm}$ and developing bond-slip laws at the fabric-matrix interface.

\section{Acknowledgements}

The authors would like to acknowledge the financial support provided by the United Arab Emirates University [grant number 31N323].

\section{References}

[1] ACI Committee 549. Guide to design and construction of externally bonded fabric-reinforced cementitious matrix (FRCM) systems for repair and strengthening concrete and masonry structures (ACI 549.4R-13). American Concrete Institute, MI, USA, 2013.

[2] S. Hashemi and R. Al-Mahaidi, "Investigation of bond strength and flexural behavior of strengthened RC beams using cement-based adhesives," Australian Journal of Structural Engineering, vol. 11, no. 2, pp. 129-139, 2010.

[3] A. D'Ambrisi, L. Feo, and F. Focacci, "Bond-slip relations for PBO-FRCM materials externally bonded to concrete," Composites Part B: Engineering, vol. 43, pp. 2938-2949, 2012.

[4] A. D'Ambrisi, L. Feo, and F. Focacci, "Experimental and analytical investigation on bond between carbon-FRCM materials and masonry," Composites Part B: Engineering, vol. 46, pp. 15-20, 2013.

[5] L. Sneed, T. D'Antino, and C. Carloni, "Investigation of bond behavior of polyparaphenylene benzobisoxazole fiberreinforced cementitious matrix composite-concrete interface," ACI Mater. J., vol. 111, no. 5, pp. 569-580, 2014.

[6] L. Sneed, T. D'Antino, and C. Carloni, and C. Pellegrino, "A comparison of the bond behavior of PBO-FRCM composites determined by double-lap and single-lap shear tests," Cem. Concr. Compos., vol. 64, pp. 37-48, 2015.

[7] L. Ombres, L., "Analysis of the bond between fabric reinforced cementitious mortar (FRCM) strengthening systems and concrete," Compos. B, vol. 69, pp. 418-426, 2015.

[8] J. Donnini, V. Corinaldesi, A. Nanni "Mechanical properties of FRCM using carbon fabrics with different coating treatments," Compos Part B Eng., vol. 88, pp. 220-228, 2016.

[9] J. Davidovits, "High-alkali cements for 21st century concretes," Special Publication, 1994, p. 144.

[10] E. Benhelal, et al., "Global strategies and potentials to curb $\mathrm{CO}_{2}$ emissions in cement industry," Journal of Cleaner Production, vol. 51, pp. 142-161, 2013.

[11] H. Herzog, B. Eliasson, and O. Kaarstad, "Capturing greenhouse gases," Scientific American, vol. 282, pp. 72-79, 2000. 
[12] Earth System Research Laboratory, Trends in Atmospheric Carbon Dioxide, 2013.

[13] E. Vasconcelos, S. Fernandes, J. Barroso de Aguiar, and F. Pacheco-Torgal, "Concrete retrofitting using metakaolin geopolymer mortars and CFRP," Construction and Building Materials, vol. 25, no. 8, pp. 3213-3221, 2011.

[14] C. Menn, D. Asprone, C. Ferone, C. Colangelo, A. Balsamo, and A. Prota, A. "Use of geopolymers for composite external reinforcement of RC members," Compos Part B Eng, vol. 45, pp. 1667-1676, 2013.

[15] F. Bencardino, A. Condello, A. and Ashour, "Single-lap shear bond tests on steel reinforced geopolymeric matrixconcrete joints," Composites Part B: Engineering, vol. 110, pp. 62-71, 2017. 